\title{
ir
}

\section{LOS TEXTOS DE LA SEGUNDA PARTE DE CALDERÓN}

\author{
Santiago Fernández Mosquera \\ Universidad de Santiago de Compostela \\ [Anuario calderoniano (ISSN: 1888-8046), 1, 2008, pp. 127-150]
}

En pocas ocasiones se tiene la oportunidad de trabajar con un corpus amplio de comedias bajo una misma perspectiva ecdótica. La labor que viene realizando el Grupo Calderón de Santiago de Compostela, dirigido por Luis Iglesias Feijoo, ha obligado a enfrentarse hasta el momento con al menos veinticuatro comedias de Calderón, las recogidas en sus partes primera y segunda ${ }^{1}$.

En distintos trabajos que han abordado hasta la fecha la situación textual de alguna de las comedias incluidas en estas dos partes, se tendía a echar en falta análisis de conjunto que permitiesen valorar lo ajustado de las conclusiones extraídas del análisis de una comedia ais$\operatorname{lada}^{2}$. Ahora, cotejadas todas, podrán alcanzarse conclusiones más fundamentadas, no por ello susceptibles de ser organizadas fácilmente en

${ }^{1}$ Este trabajo se enmarca en el Proyecto de investigación sobre la obra de Calderón financiado por la DGICYT HUM2004-03952, apoyado por el de la Xunta de Galicia PGIDT05PXIC20402PN cuyo investigador principal es Luis Iglesias Feijoo.

${ }^{2}$ A título de ejemplo, Germán Vega (2002, p. 40), en su estudio sobre testimonios sobre la Segunda parte, señala: «Pero necesitamos estudiar otras [comedias de la Segunda parte], tanto por lo que concierne a su rehabilitación textual como para tener más información sobre las características de la labor editorial de los Calderón». 
un marco totalmente sistemático. Lo que hoy expondré aquí es fruto de dicha investigación aunque referido exclusivamente a la Segunda parte que verá bien pronto la luz editada por la Fundación Castro.

Por centrarnos en la Segunda parte, quizá la parte que hasta el momento más atención de conjunto ha recibido de los estudiosos, ya el clásico artículo de Toro y Gisbert ${ }^{3}$ fundamentaba sus conclusiones en el análisis de El mayor encanto, amor, al igual que Heaton hizo veinte años después ${ }^{4}$ o más recientemente, y en su caso a partir del estudio del Judas Macabeo, Valbuena Briones ${ }^{5}$. Frente a estos trabajos más generales y que se centraban en la filiación de las distintas ediciones de la Segunda parte, otros estudios se fijaron en el texto de una comedia determinada: Max Oppenheimer jr. en El astrólogo fingido; E. M. Wilson en $A$ secreto agravio secreta venganza; José María Ruano en El mayor monstruo del mundo, y más recientemente, Germán Vega en El médico de su honra, Origen, pérdida y restauración de La Virgen del Sagrario y Amor, honor y poder, a propósito de unas sueltas de estas comedias descubiertas por él' ${ }^{6}$.

En principio, los datos externos invitarían a creer que Calderón pudo haber participado de manera activa durante la elaboración de la Segunda parte. Así, como responsable de la edición figura José Calderón, hermano del poeta (lo que podría no ser sino una mera máscara para esconder al propio dramaturgo), y a nombre del mismo don Pedro figura el privilegio de la edición, prueba de que, como mínimo, no fue ajeno por completo al proceso de preparación de esta.

A pesar de ello, todos los trabajos mencionados tendían a poner en duda la calidad textual de la Segunda parte y con ello a ser escépticos acerca de la labor que pudo desempeñar Calderón mientras se confeccionaba el volumen, aunque un estudio de conjunto de las doce comedias invita a replantearse estas conclusiones, pues muestra que, en general, y salvo en casos de reescritura, el texto de la Segunda parte suele ser el más fiable, aunque no por ello esté exento de errores, que varían según la comedia de que se trate. En efecto, el análisis conjunto conduce también a retomar el camino contrario, es decir, que, aun-

\footnotetext{
${ }^{3}$ Toro y Gisbert, 1918.

${ }^{4}$ Heaton, 1937.

${ }^{5}$ Valbuena, 1989.

${ }^{6}$ Oppenheimer, 1948; Wilson, 1958; Ruano, 1998; Vega, 2002.
} 
que sí se pueda llegar a conclusiones generales, cada comedia responde a una situación textual propia.

De la Segunda parte existen cuatro ediciones publicadas en el siglo XVII. Dos de ellas llevan la fecha de 1637; otra la de 1641, en tanto que la de Vera Tassis fue impresa en 1686 (de esta se conservan dos emisiones distintas aunque solo afectan al texto de El mayor monstruo del mundo y, en menor medida, al de Los tres mayores prodigios ${ }^{7}$ de la que tomamos dos enmiendas pertinentes para la edición de la Fundación Castro). Ya Heaton en su artículo mencionado estableció cuál era la filiación entre ellas y cuál la edición príncipe. Ciertamente, de las dos ediciones de 1637, sólo una, la que menciona en la portada a María Quiñones y a Pedro Coello (y por ello viene siendo denominada QC desde Heaton), es de dicho año, mientras que la otra, que sólo menciona a María Quiñones (Q en terminología de Heaton) es una contrahecha basada en la príncipe e impresa hacia el año 1670. La edición de 1641 (S por Carlos Sánchez) es una reedición a plana y renglón de QC, en tanto que Vera Tassis se sirvió para su edición de la contrahecha de $1670 \mathrm{Q}$, aspecto de importancia, pues algunas de las más importantes variantes de VT con respecto a la príncipe se deben a enmiendas de deturpaciones presentes en Q y no en QC. En general, podemos adelantar que en cuanto a su estado textual no bajarán de cincuenta errores las comedias que se encuentran en mejor estado en tanto que como máximo podrán superar ligeramente los cien. Téngase en cuenta que muchos de los errores enumerados son simples erratas muy fácilmente detectables como así sucede en la segunda edición S de 1641.

Sin embargo, sólo dos piezas de las doce tienen en QC testimonio único, en tanto que de las diez restantes disponemos de otros testimonios de relevancia, bien sean impresos o manuscritos. De esta manera podemos establecer diversos grupos de comedias según la situación textual que planteen.

En primer lugar están las dos comedias de las que hasta hoy no conocemos otro testimonio relevante que la Segunda parte: Argenis $y$ Poliarco y El hombre pobre todo es trazas. Otras dos cuentan además con un manuscrito unos treinta años posterior que sigue el texto de QC, aunque introduce variantes de diversa relevancia; son las dos fiestas

7 Iglesias-Caamaño, 2003. 
que enmarcan la parte: El mayor encanto, amor y Los tres mayores prodigios. Un tercer grupo estaría formado por El médico de su honra, Origen, pérdida y restauración de la Virgen del Sagrario y Amor, honor y poder. De las tres existen testimonios contemporáneos impresos, mayoritariamente sueltas, que pueden introducir variantes de distinta importancia, algo más relevantes en Amor, honor y poder. En situación similar se encuentran $A$ secreto agravio secreta venganza y El galán fantasma, de las que, además de otra impresión del XVII, conservamos testimonios manuscritos del mismo siglo, uno de 1635 firmado por Martínez de Mora en el caso de $A$ secreto agravio, y nada menos que tres en el del Galán. Por último, de tres comedias existen testimonios del XVII, manuscritos o impresos, que muestran un texto muy diferente al de QC, por lo que más propiamente habría que hablar de obras que ofrecen dos versiones. En dos de ellas, El astrólogo fingido y Judas Macabeo, el texto de QC supone una reescritura de una versión anterior, mientras que en el caso de El mayor monstruo del mundo, la de QC es una primera versión que fue reescrita en profundidad treinta años después.

Entrando en el estudio más detallado de cada texto, podría pensarse que las comedias sólo conservadas en la Segunda parte deberían ser las menos problemáticas desde el punto de vista editorial y tal premisa se cumple, hasta cierto punto, con El hombre pobre todo es trazas. Tal y como figura en QC, el texto de El hombre pobre incluye en torno a cincuenta errores que no son, además, de gran importancia pues ni se detecta ausencia de versos ni existen pasajes corruptos. Sin embargo, el de Argenis y Poliarco presenta un estado peor, ya que los errores se elevan hasta unos ochenta, entre los que destacan la omisión de un verso en un romance ${ }^{8}$ así como un pequeño pasaje de tres versos que resultan por completo absurdos dentro de la relación que declama Poliarco:

\author{
A Francia quise volverme \\ solamente por decir \\ de aquí adelante os he dicho \\ cuanto os he dicho hasta aquí. (QC)
}

\footnotetext{
${ }^{8}$ Como el sentido queda trunco, conviene restaurarlo por el verso de VT: «Pero son celos y son / vivos rayos, fuego puro, / que sin abrasar el cuerpo / penetran hasta lo oculto / del alma, donde la vida / suele convertirse en humo. / ¿Habrá entre cuantos amaron».
} 


\section{A Francia quise volverme sólo para conseguir, como su príncipe, el logro del premio que merecí. (VT)}

La restauración del pasaje exige acudir a Vera Tassis, cuya enmienda, aunque probablemente sea ajena a Calderón, encaja en el sentido del romance.

En lo que respecta a las fiestas El mayor encanto, amor y Los tres mayores prodigios, ya Germán Vega en su artículo mencionado y yo mismo en un trabajo de $2005^{9}$ suponíamos que, al haber sido compuestas y representadas respectivamente en 1635 y 1636, el texto ofrecido en la Segunda parte habría de ser bueno o cuanto menos mejor que algunas de las comedias que las acompañan. Ciertamente, ninguna de ellas pudo ser explotada durante años por una compañía antes de su edición, lo que solía conllevar una considerable degradación del texto primigenio. También podría suponerse que al haber sido ambas fiestas representadas en Palacio y no haber salido, que se sepa, de ese ámbito, Calderón podría haber mantenido un mayor control sobre su texto. El cotejo realizado nos muestra, sin embargo, que no sólo esto no sucede, sino que las fiestas ofrecen los textos con mayor número de malas lecturas de toda la parte, pues en ambos casos se superan los cien errores, entre los que destaca la omisión de tres versos en El mayor encanto, dos no recuperados por el manuscrito y otro sí por una mano posterior. Por su lado Vera detecta el error y cubre ambas lagunas con versos de su invención.

Como se anunció antes, de ambas fiestas se conservan sendos manuscritos censurados por Fermín de Sarassa y Francisco de Avellaneda, en 1668 (El mayor encanto) y en 1669 (Los tres mayores prodigios), censores también del Ms. Res.-79 parcialmente autógrafo de El mayor monstruo del mundo (censurado en 1667 y 1672), de El José de las mujeres (HSA B2612) y de El secreto a voces (HSA B2616). Los dos siguen el texto impreso de la parte introduciendo distintas enmiendas para varios de los errores del texto impreso. Merece ser subrayado que en $E l$ mayor encanto $\mathrm{Q}$ omite treinta y cinco versos con respecto a QC, laguna que pasó a VT y, en consecuencia, a Hartzenbusch. Como a los

\footnotetext{
${ }^{9}$ Vega, 2002, pp. 39-40; Fernández Mosquera, 2005, p. 316.
} 
hechos narrados en estos versos omitidos se alude en la obra un poco después, el erudito decimonónico señaló en nota la posible laguna ${ }^{10}$.

Puede subrayarse que la coincidencia tanto temporal como de los censores en estas tres comedias invita a pensar en que quizá se trate de un programa de recuperación para la corte de algunos textos tempranos de Calderón quien, aprovechando tal circunstancia, decide reescribir en profundidad el texto de El mayor monstruo para adaptarlo al ámbito cortesano mientras que, como veremos, su intervención no fue tan necesaria en las otras dos comedias por tratarse ya en un principio de fiestas palaciegas. Es más, incluso actuó, en el caso de El mayor encanto, en sentido contrario, es decir, eliminando elementos tramoyísticos complejos que sí estaban presentes en el texto de 1637 como se explicará en el trabajo de Fernando Rodríguez-Gallego.

El manuscrito de El mayor encanto, repartido entre la Hispanic Society of America (jornadas I y II, B2614) y la BNE (jornada III, Ms. 21.264/1) y tal vez copiado por Matos Fragoso, tiene el interés añadido de contar con intervenciones autógrafas de Calderón. Sánchez Mariana ${ }^{11}$ había señalado la presencia de la mano del poeta en el final de la jornada III ya que toda la espectacular escena final era sustituida por otra más breve y sencilla escrita al margen por Calderón, tal vez obedeciendo a un encargo de una nueva representación cortesana que contase con menos medios que la de treinta y tres años antes. El estudio íntegro del manuscrito realizado por Fernando Rodríguez-Gallego demuestra que la intervención de Calderón se ciñó a esa escena final ya que las distintas correcciones y apostillas salpicadas a lo largo del texto parecen obedecer a una revisión general por parte de otra mano distinta del poeta, pues así parece confirmarlo tanto la letra como la tinta (especialmente diluida) de ambas partes del manuscrito. A pesar de esta intervención final del dramaturgo, el manuscrito de El mayor encanto ofrece un texto en peor estado (omisiones de versos incluidas) que el de Los tres mayores prodigios, mucho más cuidado y sin intervención demostrada del dramaturgo. En todo caso,

${ }^{10}$ Hartzenbusch, 1944, p. 394c, nota 1.

11 Sánchez Mariana, 1984. 
ambos manuscritos suponen una valiosa ayuda para solventar las malas lecturas del texto impreso ${ }^{12}$.

Un tercer grupo estaría formado por El médico de su honra, Origen, pérdida y restauración de la Virgen del Sagrario y Amor, honor y poder. De las tres existen testimonios contemporáneos impresos — sobre todo sueltas - que pueden introducir variantes de distinta importancia, algo más relevantes en Amor, honor y poder.

De El médico de su honra sólo se conocía hasta hace poco la tradición habitual impresa de la Segunda parte. A partir de ella la editaron Jones $^{13}$ y Cruickshank ${ }^{14}$, quien declaraba que «por fortuna, el texto de nuestra obra tiene muy pocos errores obvios, y presenta pocos problemas textuales» ${ }^{15}$. En su citado trabajo de 2002, Germán Vega dio noticia de una suelta que conserva el texto de la comedia, aunque con el título El zeloso de su honra. La suelta, cuyo texto deriva del de QC, presenta, como ya señaló el mismo estudioso, dos características llamativas: por un lado, toda la terminología relativa a la medicina que se emplea en la comedia es sustituida, ya desde el título, por el término celoso y similares, aunque en otros casos se trata de versos que simplemente se eliminan. Por otro lado, las intervenciones del gracioso son drásticamente reducidas y así se suprimen tres pasajes que protagoniza. Junto a estos dos rasgos más llamativos, la suelta enmienda algunos pasajes corruptos de QC de manera diferente a como lo habían hecho otros testimonios de la Segunda parte, en especial VT. Curiosamente, y a pesar de esa apariencia de buen estado, QC presenta en torno a ochenta errores. Como irregularidad más notable se encuentra una décima anómala de doce versos que ningún otro testimonio, ni antiguo ni moderno, enmienda, pues en QC tiene sentido completo.

Situación análoga es la de Origen, pérdida y restauración de la Virgen del Sagrario. Hasta el trabajo de Germán Vega en el que da cuenta de las nuevas sueltas, los únicos testimonios del XVII para fijar su texto eran los de la Segunda parte. Vega dio noticia de dos sueltas de texto

12 Fernando Rodríguez-Gallego en este mismo volumen «Calderón revisa sus textos: a propósito de un manuscrito de El mayor encanto, amon», analiza las peculiaridades textuales de dicho manuscrito.

13 Jones, 1961.

14 Cruickshank, 1981.

15 Cruickshank, 1981, p. 63. 
muy similar (una debe de haber sido modelo de la otra) que no parecen posteriores a mediados del XVII, conservadas ambas en la BNE y que, aunque cambian el título con respecto a la princeps por Las tres edades de España, presentan un texto que sigue el de QC. Sin embargo, y como ya apuntaba el mismo Germán Vega, incluye lecturas que, al igual que sucedía con la suelta de El zeloso, permiten corregir errores de QC de manera distinta al de los demás testimonios de la Segunda parte. Sin embargo, ni estas sueltas ni toda la tradición conocida del XVII, permiten subsanar algunas deturpaciones graves que presenta el texto de la comedia, en concreto, varias ausencias de versos en tres décimas ${ }^{16}$, así como algún grave anacoluto que quizá sugiera o bien alguna laguna o bien algún otro tipo de deturpación ${ }^{17}$.

Similar aunque más complejo es el caso de Amor, honor y poder, pues son bastantes los testimonios tempranos que conservan la comedia. En las primeras ediciones fechadas se atribuye el texto a Lope de Vega: con el título de La industria contra el poder y el honor contra la fuer$z a$ aparece en El Fénix de España Lope de Vega Carpio. Veinte y tres parte de sus comedias y la mejor parte que hasta hoy se ha escrito y en la Parte veinte y ocho de comedias de varios autores (Huesca, 1634). El texto de la Parte 28 interesa menos porque sigue el de la Parte 23. En cuanto a esta, aunque data de 1629, Maria Grazia Profeti señala que la fecha debería situarse entre 1630 (año de publicación de la Parte 22) y 163233 (Parte 24) $^{18}$. Por su lado, D. W. Cruickshank indica que esta Parte 23, aunque consta publicada en Valencia, resulta ser un conjunto de sueltas que proceden de la imprenta sevillana de Simón Faxardo ${ }^{19}$. Con

16 Doce versos en total: 6 versos en una, 5 en otra y 1 en otra, recuperado este último por VT en un verso con toda probabilidad no calderoniano.

17 Sobre los problemas textuales de esta comedia trabajó Elena Marcello, 2004, y Alejandra Ulla, quien tiene en prensa un trabajo sobre el asunto y ha leído como tesis de licenciatura una edición crítica de la obra.

18 Maria Grazia Profeti, 1988, p. 36.

19 Cruickshank, 1989, p. 234: «Thus all twelve plays are clearly the work of the same printer» y Cruickshank, 2000, p. 34: «Seis de estas nueve ediciones se realizaron en Sevilla: de las seis, tres tienen un pie de imprenta falso y tres carecen de él. Para complicar aun más las cosas, las dos partes impresas en Sevilla no son en absoluto partes verdaderas, sino que están compuestas por sueltas. Para defender la causa de los libreros e impresores sevillanos hay que recordar que la Junta de Reformación, tratando equivocadamente de controlar la ética de los españoles, había prohibido, a partir de 1625, la impresión de novelas y comedias en todo el reino de Castilla (por eso 
el mismo título de La industria contra el poder..., aunque ya a nombre de Calderón, se conserva una suelta con ejemplares en la BNE y en la British Library ${ }^{20}$.

Parecen existir tres estados diferentes del texto: uno conformado por la suelta agrupada en la Parte 23 y la Parte 28, otro por la suelta exenta y otro por QC. El texto es básicamente el mismo (no parece conveniente, por ello, hablar de diferentes versiones), aunque QC presenta unos 150 versos más que los otros testimonios, mientras que estos incluyen también algunos versos no presentes en QC, aunque en ningún caso en pasajes corruptos o con lagunas detectables a través de la métrica. Por ello y por no ser tampoco relevantes para el sentido de la obra, no parece necesario incluirlos en una edición, sobre todo si entendemos que Calderón pudo haberlos eliminado al revisar la comedia con vistas a su publicación. En todo caso, tanto la suelta de la Parte 23 como en especial la suelta exenta incluyen lecturas que permiten enmendar satisfactoriamente algunos errores de la Segunda parte.

Como en el caso de las tres comedias anteriores, tanto $A$ secreto agravio secreta venganza como El galán fantasma cuentan con testimonios impresos contemporáneos de la Segunda parte, pero también con importantes testimonios manuscritos del XVII. A secreto agravio fue publicada con el título de Vengarse con fuego y agua en la misteriosa Sexta parte de comedias escogidas (Zaragoza, 1653) ${ }^{21}$, cuyo texto sigue básicamente el de QC, aunque cuenta con el interés de suprimir dos escenas de los graciosos (como en El zeloso de su honra) así como de introducir alguna corrección valiosa ${ }^{22}$. Mayor relevancia tiene un manuscrito de 1635 (dos años anterior a la edición príncipe) firmado

había que poner «Valencia» $\mathrm{y}$ «Barcelona» en los pies de imprenta falsos). Esta prohibición inútil duró diez años, pues el gobierno había de abandonarla tácitamente en 1634. Al año siguiente Calderón comenzó a hacer los preparativos para publicar su Primera parte de comedias».

${ }^{20}$ De las de la BNE había dado noticia Germán Vega, 2002, mientras que la de la British Library es señalada por Zaida Vila en su tesis de licenciatura y en un trabajo en prensa.

21 Sobre los problemas bibliográficos de esta parte puede verse Profeti, 1976.

22 Aunque con el título $A$ secreto agravio, el texto de Vengarse con fuego y agua es el reproducido en una suelta sin fecha conservada en la Hispanic Society of America (Szmuk, 2002, p. 3). 
por Diego Martínez de Mora, quien también copió cuidadosamente El sitio de Bredá y Saber del mal y el bien ${ }^{23}$. Sobre el valor textual de este manuscrito alertó Wilson en su ya mencionado artículo de 1958, en el que lo llegaba a proponer como texto base para una futura edición crítica de la comedia. El manuscrito, en efecto, nos permite solventar con eficacia algunas lagunas y malas lecturas de la edición príncipe que los distintos editores de la comedia habían tratado de corregir con diversa fortuna. Sin embargo, Wilson pasaba por alto algunas de las deficiencias del manuscrito que también omite diferentes versos sí presentes en la parte y exigidos por la métrica, y ofrece bastantes lecturas que, si bien correctas, suelen ser menos acertadas que las de $\mathrm{QC}^{24}$. El completo cotejo del manuscrito y la Segunda parte permite, en fin, editar el texto impreso en 1637 como el mejor, aunque habrá de corregirse en torno a unas sesenta ocasiones, con preferencia siguiendo lecturas del manuscrito ${ }^{25}$.

Por lo que respecta a El galán fantasma, la comedia fue publicada dentro del volumen Doce comedias las más grandiosas que hasta ahora han salido de los mejores y más insignes poetas. Segunda parte (Lisboa, 1647), en el que también figuran La dama duende y La vida es sueño. Este texto no es muy relevante para la edición de la comedia pues reproduce muy fielmente el de la Segunda parte, que sólo enmienda en casos muy obvios, aunque mantiene otros errores e incluso incluye algunos nuevos. Junto a él la comedia también se conserva en tres manuscritos custodiados en la BNE. El más interesante a primera vista es el 15672. Cuenta con censuras de 1689 y una de ellas la firma Vera Tassis, quien polemiza con otra de las censuras, en la que se recomienda la supresión de dos versos por considerarse no acordes con la doctrina cristiana, en tanto que Vera los defiende y consigue que finalmente se mantengan. Vera dice también que el texto del manuscrito sigue el editado por él, aunque el cotejo muestra que no es así y que se basa en la edición contrahecha $\mathrm{Q}$, que, a su vez, fue la base de la edición

${ }^{23}$ Ver, sobre la obra y la importancia de este manuscrito el trabajo de Yolanda Novo, 2003.

${ }^{24}$ Ver, para un detallado análisis de las relaciones entre el manuscrito y QC, Rodríguez-Gallego, 2007.

25 Este es el criterio seguido para la edición preparada para la Biblioteca Castro. Curiosamente, será esta la primera edición que tenga en cuenta el texto del manuscrito de manera sistemática a pesar de lo declarado en alguna ya publicada hace años. 
de Vera. El texto del manuscrito cuenta con diversas correcciones hechas por una segunda mano que en muchos casos coinciden con las lecturas de la edición de Vera, por lo que quizá hayan sido realizadas por el mismo amigo de Calderón ${ }^{26}$. Otro manuscrito, el 16649, no tiene fecha ni censuras, y sigue el texto del manuscrito 15672, aunque suprime muchos versos de la comedia. Estas supresiones coinciden en la mayor parte de los casos con versos atajados en el manuscrito 15672, muestra palmaria de la dependencia textual entre ambos. El otro manuscrito, el 17306, es el más relevante textualmente fuera de la tradición de la Segunda parte. Tampoco cuenta con fecha o censuras, pero su texto es muy próximo al de la Segunda parte, con algún verso añadido y con diversas, aunque siempre ligeras, variantes. No está exento, de todos modos, de algunos errores y faltan, como principal carencia, dos versos obligados que sí contiene QC:

$$
\begin{aligned}
& \text { Y vuestra alteza sea bien venido, } \\
& \text { que Julia, conociendo } \\
& \text { la seña de su amante, presumiendo } \\
& \text { que él fuese, me ha mandado } \\
& \text { El galán fantasma, QC, fol. 59v. Jornada I. } \\
& \text { Aquí pues la voz aquí } \\
& \text { en mil suspiros envuelta, } \\
& \text { en mil lágrimas bañada, } \\
& \text { dije... pero gente llega; } \\
& \text { luego, Laura, lo sabrás. }
\end{aligned}
$$$$
\text { la seña de su amante, presumiendo }
$$

LuCrecia Don Carlos está a la puerta

El galán fantasma, QC, fol. 62r. Jornada II.

Y vuestra alteza sea bien venido,

la seña de su amante, presumiendo

que él fuese, me ha mandado

El galán fantasma, Ms. 17306. Jornada I.

26 Sobre este manuscrito, ver el trabajo de Wilson citado. 
Aquí pues la voz aquí en mil suspiros envuelta, en mil lágrimas bañada, dije... pero gente llega;

Lucrecia Don Carlos está a la puerta ${ }^{27}$ El galán fantasma, Ms. 17306. Jornada I.

No obstante, su texto permite en muchos casos corregir con garantías el de la edición príncipe en especial en dos lugares. En el primero, la métrica (romance á-a) permite detectar la falta de un verso que se puede cubrir con el Ms. 17306:

Ya la di y no he de quebrarla, aunque ofendido pudiera quejarme de injurias tantas

me advierte y me desengaña; valgo yo más que yo mismo. El galán fantasma, QC, fol. 54ra. Jornada III.

Ya la di y no he de quebrarla, aunque ofendido pudiera quejarme de injurias tantas como el verle vivo aquí me advierte y me desengaña; valgo yo más que yo mismo. El galán fantasma, Ms. 17306. Jornada III ${ }^{28}$.

27 En el ms. se debió de detectar en algún momento la laguna y se añadió al margen, posiblemente ope ingenii, "Reparemos en quien viene».

${ }^{28}$ Esta es la lectura seguida en la edición preparada para la Fundación Castro; las ediciones modernas cubrían este hueco con el verso «como de vuestra osadía» procedente del ingenio veratasiano. 
En el segundo, un pasaje bastante oscuro de QC se aclara incorporando dos versos del manuscrito, no necesarios métricamente (de nuevo un romance), pero indispensables por el sentido:

\author{
Este mismo efeto, este \\ quieres que en mi pecho cause \\ tu voz, pues si cuando estoy \\ herido de tantos males \\ suele curarme el dolor \\ solamente el escucharte, \\ hoy que tuve sano el pecho \\ le hieres para que labre \\ tu voz agora la herida \\ que hubieras curado antes, \\ donde no los hay, las hacen ${ }^{29}$. \\ El galán fantasma, QC, fol. 54r. Jornada I.
}

Este mismo efeto, este quieres que en mi pecho cause tu voz, pues si cuando estoy herido de tantos males suele curarme el dolor solamente el escucharte, hoy que tuve sano el pecho le hieres para que labre tu voz agora la herida que hubieras curado antes, que a imitación de la yerba las disculpas entre amantes adonde hay celos, las curan, donde no los hay, las hacen. El galán fantasma, Ms. 17306. Jornada I.

29 Dada la difícil ilación entre los versos «que hubieras curado antes» y «adonde hay celos, las curan", tal y como figura en la Segunda parte, Hartzenbusch enmendó el segundo de ellos en "pues donde hay celos las curan». Es el único que detecta la anomalía y propone una enmienda innecesaria si acudimos a los versos del Ms. 17.306. 
En suma, también en el caso de El galán fantasma se debe seguir el de QC como texto base, aunque habrá que enmendarlo en no menos de cien ocasiones, en su gran mayoría errores evidentes ${ }^{30}$.

Por último, de otras tres comedias de la Segunda parte, existen otros testimonios del xvir, pero cuyo texto se aleja en tal medida del de la parte que hemos de hablar de versiones diferentes y en consecuencia tratarlas como textos independientes. Se trata de El mayor monstruo del mundo, Judas Macabeo y El astrólogo fingido, que han de repartirse en dos grupos distintos, pues mientras en el caso de El mayor monstruo la de QC sería una primera versión revisada treinta años después, en el de las otras dos es el texto de QC el que supone una reescritura de una versión más temprana.

El problema de las dos versiones de El mayor monstruo ya había sido puesto de relieve por sus últimos editores, que eran conscientes de este aspecto fundamental a la hora de elegir el texto base ${ }^{31}$, aunque fue Ruano de la Haza, en su artículo ya citado de 1998, quien dedicó especial atención al asunto. Ruano estableció claramente que la de QC y la del manuscrito parcialmente autógrafo Res-79 de la BNE eran versiones diferentes y por tanto nunca habrían de mezclarse en una edición, a no ser en pasajes coincidentes. Ruano no consideraba, sin embargo, ambas versiones plenamente calderonianas, pues entendía que la de QC procedía de un autor de comedias que deturpó el original del poeta. Este, treinta años después, habría intentado recuperar ese original, aunque reescribiéndolo para adecuarlo a las condiciones escénicas de la corte. Más recientemente María Caamaño coincide con Ruano en la existencia de dos versiones independientes, pero demuestra que ambas son igualmente calderonianas y rebate con eficacia los argumentos que José María Ruano había esgrimido contra la calderonicidad de la primera versión. Entendemos pues que el texto de QC es perfectamente válido y como tal puede utilizarse como base de una edición que representaría la comedia que Calderón quiso publicar en 1637. En tal edición los testimonios que reproduzcan la segunda versión de la comedia sólo podrían utilizarse para enmendar los errores de QC en aquellos pasajes que coincidan, por lo que en

30 Sobre El galán fantasma realiza su tesis de licenciatura Noelia Iglesias Iglesias.

31 Así, Ruano de la Haza, en su edición de 1989, optaba por la segunda versión mientras que Valbuena Briones editaba la versión de QC en 1995. 
los demás habría que recurrir a las otras ediciones de la Segunda parte (Vera Tassis sólo en la primera jornada ya que edita un texto híbrido de ambas versiones en las dos restantes) o bien al juicio del editor $^{32}$. Por ello mi edición para la Biblioteca Castro deja sin solventar la laguna de tres versos por tratarse de pasajes no coincidentes plenamente con la segunda versión pues su inclusión supondría la manipulación de un fragmento más amplio y no corrupto con lo que generaríamos un texto híbrido.

Las dos comedias restantes, El astrólogo fingido y Judas Macabeo, presentan, como quedó dicho, la situación inversa: el texto de QC supone una reelaboración de una versión inicial. En el caso de El astrólogo esta primer versión fue publicada en la Parte veinticinco de comedias de diferentes autores (Zaragoza, 1632, con una reedición de 1633) y era conocida desde antiguo por los estudiosos, pues ya Hartzenbusch la manejó en su edición de la comedia para la BAE. Sin embargo, el editor y dramaturgo consideró que el texto zaragozano era prueba de la corrupción del de la Segunda parte, por lo que decidió entremezclar ambos. Igual postura fue la sostenida por Max Oppenheimer jr., en su ya citado artículo de 1948 y en su posterior edición de la comedia ${ }^{33}$. Oppenheimer sostuvo explícitamente la corrupción de ambas ramas y la necesidad de sumarlas para recuperar la voluntad de Calderón, postura que llevó al extremo de editar todos los versos de ambas versiones incluso en los casos de versos alternativos o excluyentes, por lo que en su edición llegamos a encontrar disparates métricos del calibre de redondillas de cinco o seis versos y romances que no respetan su esquema métrico habitual.

Sin embargo, Fernando Rodríguez-Gallego ha demostrado que no estamos ante un caso de dos ramas textuales deturpadas, sino ante dos versiones distintas de la comedia, cada una con sentido completo. La de la Segunda parte pule y refina la de Zaragoza, trescientos versos más larga, eliminando algunas intervenciones especialmente retóricas y algunos motivos que pudiesen restar comicidad a la trama principal, ampliando una trama secundaria que pudiese servir de contrapunto a la

32 Para un análisis detallado de estas cuestiones ver los trabajos de María Caamaño, 2001a, 2001b, 2002a, 2002b, y su edición de las dos versiones procedente de su tesis de doctorado, 2006, en prensa.

33 Oppenheimer, 1994. 
de los protagonistas y limando aspectos de la versión zaragozana que remitían más directamente a la puesta en escena de la comedia ${ }^{34}$. El texto de QC, en suma, no sólo no está corrupto, sino que responde casi con seguridad a una revisión calderoniana previa a su inclusión en la Segunda parte y sólo es necesario enmendar el texto en poco más de cuarenta lugares, para lo cual nos servimos de la edición zaragozana en los pasajes coincidentes.

Análoga es la situación de Judas Macabeo, sólo que en su caso la primera versión se ha conservado no impresa, sino en dos manuscritos: uno en la BNE, Ms. 16558, que incluye la noticia de una representación de 1629 al final de la primera jornada; otro en la HSA, B2613. Como sucede en el Astrólogo, también aquí la versión inicial es considerablemente más larga (en torno a cuatrocientos versos) que la de QC. Sin embargo, la existencia de esta versión primera no había sido puesta de relieve por los estudiosos, a pesar de que al menos el manuscrito de la HSA se había manejado en algún trabajo. Se ha de añadir a esto que ni siquiera el texto de la Segunda parte era conocido en su totalidad, ya que en la edición contrahecha $Q$ se omite, por posible salto de igual a igual, toda una columna de texto de QC (un total de 33 versos), laguna que heredó Vera Tassis y, en consecuencia, Hartzenbusch y quienes le siguieron, por lo que Judas Macabeo se ha venido leyendo en sólo una de sus versiones y, además, mutilada $^{35}$. En todo caso, el texto de los manuscritos sólo podría utilizarse para enmendar el texto de QC en aquellos pasajes en que coincidiesen (destaca una décima trunca en QC que se recupera desde los manuscritos), pues de nuevo, dadas las diferencias entre ambas ramas, habremos de hablar más bien de dos versiones diferentes de la comedia. Al igual que en el caso del Astrólogo, también aquí la versión de QC revisa y pule la manuscrita, mucho más extensa y amplificatoria que la impresa en la Segunda parte ${ }^{36}$. Sirvan los pasajes siguientes como ejemplo:

${ }^{34}$ Sobre las dos versiones de El astrólogo fingido puede verse un reciente trabajo de Rodríguez-Gallego, 2006, compendio de las conclusiones alcanzadas en su memoria de licenciatura, en la que editó ambas versiones de la comedia.

35 Sólo la edición que realizo para Castro ha tenido en cuenta el texto completo de la versión de QC así como los manuscritos para su posible enmienda.

36 En la edición de Judas Macabeo trabaja Rodríguez-Gallego en una tesis doctoral que será defendida en breve. 


\section{VERSIÓN DE LOS MANUSCRITOS}

di que el sol rayaba apenas

con su luz nuestro horizonte

y la más vecina punta

coronaba de esplendores,

$y$ antes que la matutina

luz con varios arreboles

iluminase el acero

beldad que duplica soles, cuando Jonatás valiente atropellando temores por el enemigo campo, palestino Marte, rompe (jornada I)

Oíd, cobardes hebreos, abatida sucesión de la más infame sangre que Palestina crió.

Humildes samaritanos, pues la descendencia sois de aquel pueblo peregrino que Egipto tuvo en prisión; vosotros que fugitivos por la industria y el valor del alto Moisén a quien llaman capitán de Dios dejastes el ejercicio que en la sujeta prisión os daban toscos adobes de quien sois el polvo hoy $y$ huyendo por los desiertos la furia de faraón pasastes el mar Bermejo que sus ondas dividió $y$ por muros de cristal $y$ montes de agua el temor 
reparastes viendo luego cómo otra vez se juntó aquel piélago profundo que al ofendido ofensor en salado mauseolo urna de plata le dio. Vosotros que en Rafidín sin amparo $y$ con rigor esperastes tantos años la tierra de promisión sirviéndoos por alimento aquel destilado humor del alba que acaso el yelo en las flores congeló; estadme atentos, cobardes, si no os espanta mi voz, que a retar vengo ofendida de vuestro ejército a dos (jornada III)

\section{VERSIÓN DE QC}

di que el sol rayaba apenas con su luz nuestro horizonte y la más vecina punta coronaba de esplendores,

cuando Jonatás valiente atropellando temores por el enemigo campo, palestino Marte, rompe (jornada I)

Oíd, cobardes hebreos, abatida sucesión de la más humilde sangre que Palestina crió. Infames samaritanos, pues la descendencia sois 


\section{de aquel pueblo peregrino}

que Egipto tuvo en prisión;

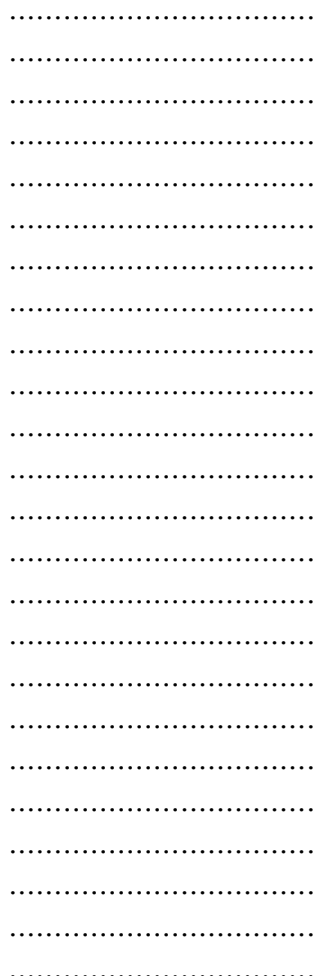

estadme atentos, infames, si no os espanta mi voz, que a retar vengo ofendida de vuestro ejército a dos (jornada III).

Vale la pena señalar que, junto a casos en los que la versión de QC pule y revisa la de los manuscritos, uno de estos, el de la BNE, incluye un misterioso pasaje al final de la segunda jornada que, por un lado, pone en escena un lance que queda sobreentendido en QC y en el manuscrito de la HSA y, por otro, introduce un componente sobrenatural al bajar un ángel que salva la vida del protagonista. 
Tras el recorrido forzadamente breve que resume de manera apretada el trabajo de investigación de varias personas en un mismo proyecto, se ha de concluir que frente a posturas no proclives a la calidad textual de QC, un análisis en conjunto demuestra que la Segunda parte de 1637 contiene por lo general los mejores textos de las doce comedias calderonianas. En efecto, la intervención del dramaturgo en la Segunda parte, a la que parece invitar que a su nombre esté el privilegio y que figure su hermano como responsable nominal de la edición, parece confirmarse a la luz del estudio textual individualizado de cada una de las comedias, pues en ninguna de ellas hay un testimonio que pueda presentarse como más autorizado que el de QC. Incluso el hecho de que El astrólogo fingido y Judas Macabeo parezcan haber sido reescritas en profundidad por Calderón con vistas a incluirlas en la Segunda parte puede verse también como prueba de la intervención activa del escritor en la gestación de la parte.

Sin embargo, esta intervención calderoniana no facilita la explicación del desigual estado textual de algunas comedias. En primer lugar, conviene recordar que, aunque Calderón revisase los textos, no corregía pruebas de imprenta y muchos de los errores detectados son problemas atribuibles a corrupciones mecánicas. Tampoco podemos descartar que la dedicación del dramaturgo no fuese igual en cada una de las comedias y que el estado en que le llegaron los distintos originales fuese diferente y con escaso grado de homogeneidad. Por otra parte, no podemos proyectar en Calderón la intención y rigor que se espera de un filólogo del siglo xxi; es decir, Calderón actúa como autor, intenta ofrecer unos buenos textos, pero no tiene por qué ser sistemático ni especialmente puntilloso con el resultado final. Calderón no es Fernando de Herrera ni un serio editor de nuestros días.

Ciertamente existen casos de tempranos testimonios manuscritos de gran calidad parangonables a la Segunda parte, como sucede con $A$ secreto agravio y El galán fantasma, aunque al no ser manifiestamente superiores parece preferible inclinarse por la versión impresa en la creencia de que Calderón pudo tener alguna responsabilidad directa en su publicación, ya que no tenemos ninguna garantía de su posible participación en los demás testimonios. Resulta curioso comprobar, no obstante, que cuando sí hay constancia de que la tuvo, como en el manuscrito de El mayor encanto, amor, su intervención no impide que dicho texto presente importantes lagunas. Como resultado de esta la- 
bor ecdótica, la edición para la Biblioteca Castro de la Segunda parte completa tomará siempre como texto base el de QC, lo que tendrá algunas consecuencias novedosas frente a ediciones anteriores de las obras completas de Calderón.

Quizá la comedia que ofrecerá un aspecto más novedoso será El astrólogo fingido, pues frente a la edición taraceada de Hartzenbusch, la de la Castro editará en exclusiva el texto de QC, entendiéndolo como una segunda versión de la comedia.

Novedosa será también la edición de Judas Macabeo por recuperar íntegro el texto de QC y servirse de manera preferente de los manuscritos para enmendar los pasajes corruptos de la parte.

En lo que respecta a $A$ secreto agravio secreta venganza y El galán fantasma, además de recuperar el texto de QC, se ha enmendado utilizando sistemáticamente los manuscritos mencionados.

Para las comedias Origen, pérdida y restauración de la Virgen del Sagrario, Amor, honor y poder y El médico de su honra, se han tenido en cuenta por primera vez las sueltas descubiertas por Germán Vega.

En la edición de las dos fiestas, El mayor encanto, amor y Los tres mayores prodigios, se han empleado por primera vez los dos manuscritos de 1668 y 1669 respectivamente, el primero con intervenciones autógrafas de Calderón. Además se recuperan treinta y cinco versos que se omitían en $\mathrm{Q}$, omisión heredada por toda la tradición posterior.

En cuanto a Argenis y Poliarco y El hombre pobre todo es trazas el texto estará depurado de las intervenciones debidas al ingenio de Vera Tassis.

Por último, en lo que respecta a El mayor monstruo del mundo, y aunque ya se había editado anteriormente según la versión de QC, en la edición Castro se seguirá el texto de la Segunda parte sin añadidos innecesarios procedentes de la segunda versión o de Vera Tassis.

En suma, se ha intentado recuperar el Calderón más genuino, libre de las contaminaciones de Vera Tassis que habían sido mantenidas e incluso aumentadas por los editores posteriores. En fin, un Calderón en limpio tal y como el proyecto para la Biblioteca Castro tiene por objetivo principal. 


\section{Bibliografía}

CaAmaño Rojo, M., "El mayor monstruo del mundo" de Calderón de la Barca. Estudio textual, Santiago de Compostela, Universidad de Santiago de Compostela, 2001a.

— «Los cánones trágicos y la comedia áurea española: El mayor monstruo del mundo», en Homenaje a Benito Varela Jácome, ed. Á. Abuín González, J. Casas y J. M. González Herrán, Santiago de Compostela, Universidad de Santiago de Compostela, 2001b, pp. 23-45.

- «El mayor monstruo del mundo, de Calderón: reescritura y tradición textual», Criticón, 86, 2002a, pp. 139-157.

- «Notas al título de una tragedia calderoniana», en Homenaxe a Fernando R. Tato Plaza, ed. R. Lorenzo, Santiago de Compostela, Universidad de Santiago de Compostela, 2002b, pp. 435-445.

- Edición crítica de "El mayor monstruo del mundo", de Calderón, Tesis de Doctorado dirigida por S. Fernández Mosquera, Santiago de Compostela, Universidade de Santiago de Compostela, junio 2006.

Calderón de la Barca, P., El mayor monstruo del mundo, ed. J. M. Ruano de la Haza, Madrid, Espasa Calpe, 1989.

- El mayor monstruo del mundo, ed. Á. Valbuena Briones, Newark, Juan de la Cuesta, 1995.

- El médico de su honra, ed. C. A. Jones, Oxford, OUP, 1961.

- El médico de su honra, ed. D. W. Cruickshank, Madrid, Castalia, 1981.

- The Fake Astrologer, ed. y trad. M. Oppenheimer, New York, Peter Lang, 1994.

Cruickshank, D. W., "Some Notes on the Printing of Plays in Seventeenth Century Seville», The Library, 5, 11, 1989, pp. 231-252.

- «Los textos de Calderón», en Calderón en el 2000, ed. L. Iglesias Feijoo, Ínsula, 644-655, 2000, pp. 33-35.

Fernández Mosquera, S., «Defensa e ilustración de la Segunda parte (1637) de Calderón de la Barca», en Estudios de teatro español y novohispano, ed. M. Romanos, F. Calvo y X. González, Buenos Aires, Universidad de Buenos Aires / AITENSO, 2005, pp. 303-325.

Hartzenbusch, J. E., ed., Obras de don Pedro Calderón de la Barca. Tomo I, [BAE, 7, 1862], Madrid, Atlas, 1944.

Heaton, H. C., «On the Segunda parte of Calderón», Hispanic Review, 5, 1937, pp. 208-224.

Iglesias Feijoo, L., y M. CaAmaño Rojo, «Calderón, del texto a la escena. Con la noticia de una nueva Segunda parte de Vera Tassis», en Teatro calderoniano sobre el tablado. Calderón y su puesta en escena a través de los siglos. XIII Coloquio Anglogermano sobre Calderón. Florencia, 10-14 de julio de 2002, Stuttgart, Franz Steiner Verlag, 2003, pp. 207-233. 
Marcello, E. E., «De Valdivielso a Calderón: Origen, pérdida y restauración de la Virgen del Sagrario», Criticón, 91, 2004, pp. 79-91.

Novo, Y., "A vueltas con los manuscritos calderonianos: notas para la edición crítica de Saber del mal y del bien", Criticón, 87-88-89, 2003, pp. 577-587.

Oppenheimer, M. jr., "Addenda on the Segunda parte of Calderón», Hispanic Review, 16, 1948, pp. 335-340.

Profeti, M. ${ }^{a}$ G., «Un enigma bibliográfico: la Parte VI de Comedias Nuevas Escogidas", Annali della Facoltà di Economia e Commercio di Verona, Verona, 1976, pp. 5-18.

- La collezione "Diferentes autores», Kassel, Reichenberger, 1988.

Rodríguez-Gallego, F., "Sobre el valor textual de la Segunda parte de comedias de Calderón: a propósito de $A$ secreto agravio secreta venganza», III Congreso Internacional de ALEPH: en Teoría hablamos de Literatura, Granada, 3-7 abril de 2006. En prensa.

- «El astrólogo fingido» de Pedro Calderón de la Barca: estudio textual y edición de las dos versiones, Tesis de Licenciatura dirigida por Santiago Fernández Mosquera, Santiago de Compostela, Universidad de Santiago de Compostela, 2004.

- «Noticia de las dos versiones de El astrólogo fingido de Calderón de la Barca», en Campus Stellae. Haciendo camino en la investigación literaria, coord. D. Fernández López, F. Rodríguez-Gallego et al., Santiago de Compostela, Universidad de Santiago de Compostela, 2006 (2 vols.), vol. I, pp. 456465.

- «Sobre el manuscrito BNE 14927 de A secreto agravio secreta venganza y el valor textual de la Segunda parte de comedias de Calderón", Criticón, 99, 2007, pp. 217-241.

RuANO de la Haza, J. M., "Las dos versiones de El mayor monstruo del mundo, de Calderón», Criticón, 72, 1998, pp. 35-47.

SÁnchez Mariana, M., "Un manuscrito calderoniano desconocido (con una digresión sobre los autógrafos de Matos Fragoso)», Revista de Literatura, 46, 91, 1984, pp. 121-130.

Szmuk, S. E., Calderón sueltas in the collection of The Hispanic Society of America, Kassel, Reichenberger, 2002.

Toro y Gisbert, M. de, "¿Conocemos el texto verdadero de las comedias de Calderón?», Boletín de la Real Academia Española, 5, 1918, pp. 401-421.

Ulla Lorenzo, A., "Origen, pérdida y restauración de la Virgen del Sagrario» de Pedro Calderón de la Barca:estudio textual y edición crítica, Tesis de Licenciatura dirigida por S. Fernández Mosquera, Santiago de Compostela, Universidad de Santiago de Compostela, 2006.

- «Notas para una edición crítica de Origen, pérdida y restauración de la Virgen del Sagrario» de Pedro Calderón de la Barca», III Congreso Internacional de 
ALEPH: En Teoría hablamos de Literatura, Granada, 3-7 abril de 2006. En prensa.

VAlbuena Briones, Á., «Una metodología para precisar los textos de la Segunda parte de comedias de Calderón", en Estudios sobre Calderón y el teatro de la Edad de Oro. Homenaje a Kurt y Roswitha Reichenberger, ed. F. Mundi Pedret, Barcelona, PPU, 1989, pp. 39-46.

Vega García-Luengos, G., «Calderón, nuestro problema (bibliográfico y textual): más aportaciones sobre las comedias de la Segunda parte», en Ayer y hoy de Calderón. Actas seleccionadas del Congreso Internacional celebrado en Ottawa del 4 al 8 de octubre del 2000, ed. J. M. ${ }^{a}$ Ruano de la Haza y J. Pérez Magallón, Madrid, Castalia, 2002, pp. 37-62.

Vila Carneiro, Z., «Hacia una edición crítica de la comedia Amor, honor y poder de don Pedro Calderón de la Barca», III Congreso Internacional de ALEPH: en Teoría hablamos de Literatura, Granada, 3-7 abril de 2006. En prensa.

- Amor, honor y poder de Calderón de la Barca. Estudio textual y edición crítica, Tesis de Licenciatura dirigida por S. Fernández Mosquera, Santiago de Compostela, Universidad de Santiago de Compostela, 2006.

WiLsOn, E. M., «Notes on the text of $A$ secreto agravio secreta venganza», Bulletin of Hispanic Studies, 35, 1958, pp. 72-82; reed. en P. Calderón de la Barca, Comedias, edición facsímil a cargo de D. W. Cruickshank y J. E. Varey, vol. I, The textual criticism of Calderón's Comedias, ed. D. W. Cruickshank, London, Tamesis, 1973, pp. 95-106. 